\title{
How Accurate are Government Forecasts of Economic Fundamentals? The Case of Taiwan ${ }^{1}$
}

\author{
Chia-Lin Chang \\ Department of Applied Economics \\ National Chung Hsing University \\ Taiwan \\ Philip Hans Franses ${ }^{2}$ \\ Econometric Institute \\ Erasmus School of Economics \\ The Netherlands \\ Michael McAleer \\ Department of Applied Economics \\ National Chung Hsing University \\ Taichung, Taiwan \\ and \\ Econometric Institute \\ Erasmus School of Economics \\ The Netherlands \\ and \\ Tinbergen Institute \\ The Netherlands
}

Econometric Institute Report 2009-09

This version: July 2009

\footnotetext{
${ }^{1}$ This paper was initiated while the third author was visiting the Department of Quantitative Economics, Complutense University of Madrid, whose gracious hospitality and excellent working environment are greatly appreciated. For financial support, the first and third authors wish to thank the National Science Council, Taiwan and the Australian Research Council, respectively.

${ }^{2}$ Address for correspondence: PH Franses, Econometric Institute, Erasmus School of Economics, PO Box 1738, NL3000 DR Rotterdam, The Netherlands, franses@ese.eur.nl
} 


\begin{abstract}
A government's ability to forecast key economic fundamentals accurately can affect business confidence, consumer sentiment, and foreign direct investment, among others. A government forecast based on an econometric model is replicable, whereas one that is not fully based on an econometric model is non-replicable. Governments typically provide non-replicable forecasts (or, expert forecasts) of economic fundamentals, such as the inflation rate and real GDP growth rate.

In this paper, we develop a methodology to evaluate non-replicable forecasts. We argue that in order to do so, one needs to retrieve from the non-replicable forecast its replicable component, and that it is the difference in accuracy between these two that matters. An empirical example to forecast economic fundamentals for Taiwan shows the relevance of the proposed methodological approach. Our main finding is that it is the undocumented knowledge of the Taiwanese government that reduces forecast errors substantially.
\end{abstract}

Keywords: Government forecasts, generated regressors, replicable government forecasts, nonreplicable government forecasts, initial forecasts, revised forecasts.

JEL classifications: C53, C22, E27, E37. 


\section{Introduction}

Governments typically provide forecasts of economic fundamentals, such as the inflation rate and real GDP growth rate. A government's ability to provide initial and updated forecasts of key economic fundamentals accurately can affect, for example, business confidence, consumer sentiment, and foreign direct investment.

Econometric models are frequently used to provide forecasts in economics and business. Such model-based forecasts can be adjusted by governments for a variety of reasons (see, for example, Goodwin (2000), Franses (2008)). A government forecast that is based on an econometric model is replicable, whereas a government forecast that is not based on an econometric model is nonreplicable. Governments can, and do, provide both replicable and non-replicable forecasts. In virtually all cases, information on how a model-based forecast is translated into an non-replicable forecast is not recorded.

In this paper, we develop an econometric model to generate replicable government forecasts (called expertise), compare replicable and non-replicable government forecasts using efficient estimation methods, and present a direct test of expertise that is contained in government forecasts. The key motivation to do this is because it allows us to properly evaluate government forecasts. Indeed, before evaluating non-replicable forecasts, one needs to construct the replicable part. An empirical example to forecast economic fundamentals for Taiwan shows the relevance of the methodological approach proposed in the paper.

The empirical analysis shows that replicable and non-replicable government forecasts can lead to markedly different results. Alternative estimation and inferential methods can lead to significantly different outcomes. Initial and revised government forecasts of economic fundamentals can also differ substantially. Taken together this shows that alternative models and methods can, and do, lead to distinct differences in the evaluation of the accuracy of government forecasts.

The plan of the remainder of the paper is a follows. Section 2 presents the econometric model specification, analyses replicable and non-replicable government forecasts, presents the measurement error problem in obtaining initial and revised government forecasts, considers optimal

forecasts and efficient estimation methods, and presents a direct test of expertise contained in 
government forecasts. The data analysis and a relevant empirical example are discussed in Section 3. Some concluding comments are given in Section 4.

\section{Model Specification}

In this section we present an econometric model for government forecasts. This will enable the generation of replicable government forecasts from non-replicable government forecasts, and permit a comparison to be made with non-replicable government forecasts.

Let an econometric model of the government for initial and revised forecasts for the variable of interest, $y$, be given as

$$
y=Z \gamma+\beta_{i} X_{i}^{*}+u_{i}, \quad u_{i} \sim\left(0, \sigma_{u}^{2} I\right)
$$

where $i=1, \ldots m$, where $m$ is the range of updated forecasts. $y$ is a $T \mathrm{x} 1$ vector of observations to be explained (typically, an economic fundamental, such as the inflation rate or the rate of growth of real GDP), $Z$ is a $T \mathrm{x} g$ matrix of $T$ observations on $g$ variables that are publicly available, and $X_{i}^{*}$ is the latent (unobserved) expertise of government forecast $i$. It is also assumed that $E\left(Z u_{i}\right)=0$ and $E\left(X_{i}^{*} u_{i}\right)=0$. The assumptions on the error term in (1) can be relaxed easily.

If $X_{i}^{*}$ were to comprise observable data, ordinary least squares [OLS] for (1) would be consistent and efficient, and hence optimal in estimation. Under the assumption of correct specification and a mean squared error (MSE) loss function, the optimal forecast of $y$, given the information set, is its conditional expectation (see Patton and Timmermann (2007a, 2007b)).

Let the $T \mathrm{x} 1$ vector, $X_{i}$, represent the observable (that is, announced) government forecast $i$, which can partly or fully be based on an econometric model, which is unknown. The relationship between this non-replicable government forecast, $X_{i}$, and the expertise contained in government forecast $i$, is assumed to be given by

$$
X_{i}=X_{i}^{*}+\eta_{i}, \quad \eta_{i} \sim\left(0, \sigma_{i}^{2} I\right)
$$


where $i=1, \ldots, m$, and $\eta_{i}$ is a $T \times 1$ vector, and it denotes the measurement error in government forecast $i$. It is assumed that $X_{i}^{*}$ and $\eta_{i}$ are uncorrelated for all $i$.

The observed non-replicable government forecast is assumed to be modelled as

$$
X_{i}=W_{i} \delta_{i}+\eta_{i}, \quad \eta_{i} \sim\left(0, \sigma_{i}^{2} I\right)
$$

where the $T$ x $k_{i}$ matrix $W_{i}$ is the information set available in obtaining the non-replicable government forecast $i$ at time $t$-1. It is assumed that $E\left(W_{i} \eta_{i}\right)=0$ for all $i, \delta_{i}$ is a $k_{i} \mathrm{x} 1$ vector of unknown parameters, and

$$
W_{i} \subset I_{-1}^{i}
$$

$i=1, \ldots, m, I_{-1}^{i}$ is the information set for the non-replicable government forecast $i$ at time $t-1$. As $Z$ in (1) is common knowledge, it follows from (4) that

$$
\left\{Z, W_{i}\right\} \subset I_{-1}^{i},
$$

for all $i=1, \ldots, m$. The information set $I_{-1}^{i}$ is used to obtain optimal forecasts of $y$ under a MSE loss function. It should be emphasized that an econometric model enables optimal forecasts to be generated, and hence the absence of an econometric model means that optimal forecasts under a MSE loss function can not be obtained.

It follows from (3) that

$$
E\left(X_{i} \mid I_{-1}^{i}\right) \equiv X_{i}^{*}=W_{i} \delta_{i}
$$

where $W_{i} \delta_{i}$ denotes the observable expertise of the non-replicable government forecast $i$. The rational expectation in (5) is a replicable government forecast, and its estimate is given as 


$$
\hat{X}_{i}^{*}=\hat{X}_{i}=W_{i} \hat{\delta}_{i}=W_{i}\left(W_{i}^{\prime} W_{i}\right)^{-1} W_{i}^{\prime} X_{i}=P_{i} X_{i}
$$

where $P_{i}$ is the standard 'hat' matrix. Equation (6) shows that the latent government expertise for forecast $i, X_{i}^{*}$, can be obtained as an estimate of the observable non-replicable government forecast, $\hat{X}_{i}$. It is well known that the use of rational expectations reduces the number of unknowns in (5) from $T$ to $k_{i}$, where $k_{i}<<T$ for all $i$.

Replacing the unobservable $X_{i}^{*}$ in (1) with the observable $\hat{X}_{i}$ gives

$$
y=Z \gamma+\beta_{i} \hat{X}_{i}+\varepsilon_{i}
$$

where

$$
\begin{aligned}
\varepsilon_{i} & =u_{i}+\beta_{i}\left(X_{i}^{*}-\hat{X}_{i}\right) \\
& =u_{i}+\beta_{i}\left(W_{i} \delta_{i}-P_{i} X_{i}\right) \\
& =u_{i}+\beta_{i}\left(W_{i} \delta_{i}-P_{i}\left(W_{i} \delta_{i}+\eta_{i}\right)\right) \\
& =u_{i}-\beta_{i} P_{i} \eta_{i}
\end{aligned}
$$

which is a composite error term, involving the measurement error, $\eta_{i}$, of the non-replicable government forecast $i$. If $\beta_{i}=0$ for all $i$, in which case the government uses econometric model (1) including only publicly available information, it follows that $\varepsilon_{i}=u_{i}$ for all $i$.

The correlation between $\hat{X}_{i}$ and $\varepsilon_{i}$ is $-\beta_{i} \delta_{i}^{2}\left(T-k_{i}\right)$, but OLS for the parameters in (7) is consistent as $\hat{X}_{i}$ is asymptotically uncorrelated with $\varepsilon_{i}$ for all $i$.

If $u_{i}$ and $\eta_{i}$ are mutually uncorrelated, then

$$
V=E\left(\varepsilon_{i} \varepsilon_{i}{ }^{\prime}\right)=E\left(u_{i} u_{i}{ }^{\prime}\right)+\beta_{i}^{2} P_{i} E\left(\eta_{i} \eta_{i}{ }^{\prime}\right) P_{i}
$$

so that 


$$
V=\sigma_{u}^{2} I+\beta_{i}^{2} \sigma_{i}^{2} P_{i}, \quad i=1, \ldots, m
$$

It is obvious that serial correlation and heteroskedasticity are present in (9) through the measurement error $\eta_{i}$ in $X_{i}$ in (2). Thus, if OLS is used to estimate (7), the correct covariance matrix in (9), or a consistent estimator such as the Newey-West HAC covariance matrix, should be used.

The necessary and sufficient conditions for OLS to be efficient in the presence of serial correlation and heteroskedasticity are given in Kruskal's theorem, of which a special case is the Gauss-Markov Theorem (see, for example, McAleer (1992), Fiebig et al. (1992), McAleer and McKenzie (1991), and more recently, Franses et al. (2009)), and are given by

$$
\begin{aligned}
& \text { (i) } V Z=Z A_{1} \text {, for some } A_{1} \\
& \text { (ii) } V \hat{X}_{i}=\hat{X}_{i} A_{2}, \text { for some } A_{2}
\end{aligned}
$$

Condition (i) is satisfied if $Z \perp W_{i}$ or if $Z \subset W_{i}$, while condition (ii) is satisfied automatically as $\hat{X}_{i}=P_{i} X_{i}$ in (6). In short, generalized least squares [GLS] is equivalent to OLS because the first step of the two step OLS estimator is satisfied as the transformation matrix is proportional to the data matrix.

Defining $G_{i}=\left[Z_{i}: \hat{X}_{i}\right]$ and $\phi_{i}{ }^{\prime}=\left(\gamma^{\prime}, \beta_{i}{ }^{\prime}\right)$ for all $i$, (7) may be rewritten as

$$
y=G_{i} \phi_{i}+\varepsilon_{i}
$$

If conditions (i) and (ii) are satisfied, OLS is efficient for $\phi_{i}$ and the correct OLS covariance matrix is given by

$$
\operatorname{var}\left(\hat{\phi}_{i}\right)=\left(G_{i}{ }^{\prime} G_{i}\right)^{-1} G_{i}{ }^{\prime} V G_{i}\left(G_{i}{ }^{\prime} G_{i}\right)^{-1}
$$

where $V$ is given in (9). Substitution for $V$ in (11) gives 


$$
\operatorname{var}\left(\hat{\phi}_{i}\right)=\sigma_{u}^{2}\left(G_{i}{ }^{\prime} G_{i}\right)^{-1}+\beta_{i}^{2} \sigma_{i}^{2}\left(G_{i}{ }^{\prime} G_{i}\right)^{-1} G_{i}{ }^{\prime} P_{i} G_{i}\left(G_{i}{ }^{\prime} G_{i}\right)^{-1},
$$

which shows that the standard OLS covariance matrix of $\hat{\phi}_{i}$, namely $\sigma_{u}^{2}\left(G_{i}{ }^{\prime} G_{i}\right)^{-1}$, gives a downward bias in the covariance matrix and an upward bias in the corresponding t-ratios (see Pagan (1984) and Oxley and McAleer (1993) for examples in the case of generated regressors).

An alternative to estimating equation (7) is to substitute from (2) directly into (1) to obtain

$$
y=Z \gamma+\beta_{i}\left(X_{i}-\eta_{i}\right)+u_{i}
$$

or

$$
y=Z \gamma+\beta_{i} X_{i}+\left(u_{i}-\beta_{i} \eta_{i}\right)
$$

It is clear that OLS is inconsistent for (13) as $X_{i}$ is correlated with $\eta_{i}$. Therefore, GMM should be used if the non-replicable government forecast, $X_{i}$, is used to explain the variable of interest, $y$.

The effect of measurable government expertise, $W_{i}$, on the non-replicable government forecast, $X_{i}$, can be tested directly in (3), in which case OLS is efficient given the information set. Moreover, the conditional expectation of $X_{i}$ is an optimal forecast under a MSE loss function.

An important by-product of this framework is that when $\gamma=0$, models (7) and (13) reduce to the test regressions to examine forecast unbiasedness. Indeed, (7) becomes

$$
y=\gamma_{i}+\beta_{i} \hat{X}_{i}+\varepsilon_{i}
$$

and (13) becomes

$$
y=\gamma_{i}+\beta_{i} X_{i}+\left(u_{i}-\beta_{i} \eta_{i}\right)
$$

and the null hypothesis of no bias corresponds with $\gamma_{i}=0$ and $\beta_{i}=1$. 
In summary, what should an analyst do in examining the accuracy of government forecasts? First, the analyst needs to collect data on $W_{i}$ and, if possible, on $Z$, and estimate (3) to compute the replicable forecast. The model statistics give an impression as to what extent the government might have used an econometric model to create the overall non-replicable forecast. The analyst can then examine the potential bias in the replicable and non-replicable forecasts. It is known from the literature on forecasting SKU level sales data, where experts frequently adjust model-based forecasts, that expert forecasts are often biased (Fildes et al, 2009, Franses and Legerstee, 2009). Finally, the analyst can compute forecast error statistics, such as root mean squared prediction errors [RMSPE] or mean absolute deviation [MAD], for the replicable and non-replicable forecasts to examine how much any undocumented knowledge in the non-replicable forecasts can contribute to forecast accuracy.

\section{Government forecasts in Taiwan}

In this section we examine the accuracy of government forecasts and we also compare the quality of replicable and non-replicable forecasts. Since 1978, actual data and initial, primary and revised forecasts of economic fundamentals in Taiwan have been released by the government, as follows:

(i) In Q1 (February), release (initial) forecasts for Q1, Q2, Q3 and Q4 in the same year; and Q3 (primary value) and Q4 (revised forecast) in the previous year;

(ii) In Q2 (May), release (initial) forecasts for Q2, Q3 and Q4 in the same year; Q1 and Q2 for the

following year; Q4 (primary value) for the previous year; and Q1 (revised forecast) in the same year; (iii) In Q3 (August), release (initial) forecasts for Q3 and Q4 in the same year; Q1 (primary value) and Q2 (revised forecast) in the same year;

(iv) In Q4 (November), release (initial) forecasts for Q4 in the same year; Q1, Q2, Q3 and Q4 in the following year; and Q2 (primary value) and Q3 (revised forecast) in the same year.

Thus, there are several forecasts for each period, even considering just the one-quarter ahead forecasts, namely the initial forecast made in the same period, the primary forecast that is made available one quarter later, and the revised value that is available two quarters later. Only the initial forecast is a one-quarter forecast, with both the primary and revised forecasts being revisions of the initial forecast. 
The data are obtained from the Quarterly National Economic Trends, Directorate-General of Budget, Accounting and Statistics, Executive Yuan, Taiwan, 1978-2008. The sample period used for the actual and government forecasts of seasonally unadjusted quarterly inflation rate and real growth rate of GDP is 1978 Q1 to 2008 Q1. Actual data on the inflation rate and real growth rate, as well as the initial and primary forecasts, are used in the empirical analysis. As there are some missing observations in the revised forecasts of both the inflation rate and real growth rate, revised forecasts are not considered in the empirical analysis. So, the initial forecasts are $i=1$ and the primary forecasts correspond with $i=2$.

Insert Figure 1 about here

Insert Figure 2 about here

The actual, initial and primary forecasts of the inflation rate are given in Figure 1, while the real growth rate counterparts are shown in Figure 2. Both figures show that the actual data, initial forecasts and primary forecasts of the inflation rate and real growth rate are reasonably similar, with most turning points being forecast accurately.

Insert Table 1 about here

Table 1 provides a formal test of the effects of government expertise on non-replicable initial and primary forecasts in equation (3). Government expertise for the primary forecast in (3) is approximated by one-period lagged real growth, one-period lagged inflation, one period lagged initial forecast, and one period lagged primary forecast, while government expertise for the initial forecast replaces the one period lagged primary forecast with its two period lagged counterpart. The lagged inflation rate is significant in both the non-replicable initial and primary forecasts of the inflation rate, and the lagged real growth rate is significant in both the non-replicable initial and primary forecasts of the real growth rate. Overall, the number of individually significant variables is greater for the non-replicable primary forecasts of both the inflation rate and the real growth rate than for their non-replicable initial forecast counterparts. The fit of the models is quite high, and hence the unexplained variance (corresponding to undocumented knowledge of the government forecasters) is somewhere in between $10 \%$ and $25 \%$.

Insert Table 2 about here 
The bias in the replicable initial and primary forecasts on the inflation rate and real growth rate in equation (7) is tested in Table 3, using OLS and both the OLS and Newey-West HAC standard errors. For the inflation rate, the replicable initial and primary forecasts are both highly significant, with the estimated coefficients being virtually indistinguishable from unity, especially for the replicable primary forecast. So, there is no bias here. A different qualitative interpretation holds for the replicable initial and primary forecasts of the real growth rate, as the estimated coefficients are significantly greater than unity for both the replicable initial and primary forecasts. Apparently the an analyst can improve on deriving replicable forecasts by including alternative explanatory variables in $W_{i}$. The biased OLS standard errors are considerably smaller than their Newey-West HAC counterparts, especially for the inflation rate. The goodness-of-fit of the replicable initial and primary forecasts are very similar as the replicable forecasts use similar information sets.

Insert Table 3 about here

Table 3 provides a formal test of bias in the non-replicable initial and primary forecasts in equation (13) using OLS and GMM estimation. The instrument list for GMM for the primary forecast includes one-period lagged real growth, one-period lagged inflation, one-period lagged initial forecast, and one-period lagged primary forecast, while the instrument set for the initial forecast replaces the one period lagged primary forecast with its two period lagged counterpart. The OLS and GMM estimates are qualitatively the same in all cases, and are numerically quite similar for the non-replicable initial and primary forecasts for the inflation rate, and the non-replicable primary forecast of the real growth rate.

The results in Table 3 suggest that the estimated coefficients of the non-replicable initial and primary forecasts of the inflation rate are indistinguishable from unity, as in Table 2, whereas those of the real growth rate are significantly greater than unity. However, the non-replicable primary forecasts of both the inflation rate and real growth rate would seem to be more accurate than their non-replicable initial forecast counterparts.

The results in Tables 2 and 3 show that forecasts for real growth rates are biased, while the forecasts for inflation are generally unbiased. If we compare the estimated parameters across Tables 2 and 3, then we see that the bias is larger for the replicable forecasts than for the non-replicable forecasts of the growth rates. Apparently, the government experts are able to reduce the model-based bias. 


\section{Insert Table 4}

The apparent ability of Taiwanese government experts to improve forecast quality is further substantiated by the results in Table 4 . The non-replicable forecasts show an improvement in accuracy across all variables and criteria, with the improvement being greatest for primary forecasts and, especially, inflation.

In summary, the empirical results suggest that both the initial and primary forecasts are reasonably accurate measures of the inflation rate and the real growth rate for Taiwan. As the primary forecast is an updated measure of the initial forecast, it is not altogether surprising that it provides a more accurate forecast of both economic fundamentals.

\section{Concluding Remarks}

A government's ability to provide accurate initial and updated forecasts of key economic fundamentals, such as the inflation rate and real GDP growth rate, can affect, for example, business confidence, consumer sentiment, and foreign direct investment. Econometric models are frequently used to provide initial and updated forecasts in economics and business, and such model-based forecasts can be adjusted by governments for a variety of reasons. A government forecast that is based on an econometric model is replicable, whereas a government forecast that is not based on an econometric model is non-replicable. Governments can, and do, provide both replicable and nonreplicable forecasts. Moreover, government forecasts are regularly updated, as can be seen by the frequent revisions that are made to initial, and even updated, official forecasts.

The empirical analysis for actual and government forecasts of the quarterly inflation rate and real growth rate of GDP for Taiwan from 1978 Q1 to 2008 Q1 showed that replicable and nonreplicable government forecasts were distinctly different from each other, that efficient and inefficient estimation methods, as well as consistent and inconsistent covariance matrix estimates, led to significantly different outcomes, that government forecasts of economic fundamentals differed markedly between initial and primary (or updated) forecasts, and that alternative models and methods led to differences in the accuracy of initial and primary government forecasts. The replicable and non-replicable estimated of primary forecasts were generally found to be more accurate than their initial forecast counterparts. Our main finding is that it is the undocumented knowledge of the Taiwanese government that reduces forecast errors substantially. 
The theoretical and empirical analysis presented in the paper can be used more widely for a range of economic fundamentals that involve initial and updated official forecasts. 
Table 1

Generating Replicable Expertise in Non-Replicable Initial and Primary Forecasts
(standard errors in parentheses)

\begin{tabular}{|c|c|c|c|c|}
\hline \multirow{2}{*}{$\begin{array}{l}\text { Included } \\
\text { Variables }\end{array}$} & \multicolumn{2}{|c|}{ Inflation } & \multicolumn{2}{|c|}{ Real Growth Rate } \\
\hline & $\begin{array}{c}\text { Non-Replicable } \\
\text { Initial Forecast }\end{array}$ & $\begin{array}{l}\text { Non-Replicable } \\
\text { Primary Forecast }\end{array}$ & $\begin{array}{l}\text { Non-Replicable } \\
\text { Initial Forecast }\end{array}$ & $\begin{array}{l}\text { Non-Replicable } \\
\text { Primary Forecast }\end{array}$ \\
\hline Intercept & $\begin{array}{c}0.112 \\
(0.283)\end{array}$ & $\begin{array}{l}-0.351 \\
(0.331)\end{array}$ & $\begin{array}{l}1.285^{* *} \\
(0.283)\end{array}$ & $\begin{array}{l}1.657 * * \\
(0.358)\end{array}$ \\
\hline Real Growth $(t-1)$ & $\begin{array}{c}0.056 \\
(0.035)\end{array}$ & $\begin{array}{l}0.084^{*} \\
(0.041)\end{array}$ & $\begin{array}{c}0.589 * * \\
(0.081)\end{array}$ & $\begin{array}{c}0.584^{* *} \\
(0.229)\end{array}$ \\
\hline Inflation $(t-1)$ & $\begin{array}{c}0.865 * * \\
(0.125)\end{array}$ & $\begin{array}{c}0.901 * * \\
(0.302)\end{array}$ & $\begin{array}{c}0.012 \\
(0.024)\end{array}$ & $\begin{array}{c}0.005 \\
(0.030)\end{array}$ \\
\hline Initial Forecast (t-1) & $\begin{array}{c}0.018 \\
(0.158)\end{array}$ & $\begin{array}{c}0.030 \\
(0.189)\end{array}$ & $\begin{array}{c}0.068 \\
(0.136)\end{array}$ & $\begin{array}{c}-0.550 * * \\
(0.155)\end{array}$ \\
\hline Primary Forecast $(t-1)$ & & $\begin{array}{c}0.006 \\
(0.370)\end{array}$ & & $\begin{array}{c}0.622 * * \\
(0.300)\end{array}$ \\
\hline Primary Forecast $(t-2)$ & $\begin{array}{c}0.019 \\
(0.084)\end{array}$ & & $\begin{array}{c}0.050 \\
(0.081)\end{array}$ & \\
\hline Adjusted $\mathrm{R}^{2}$ & 0.916 & 0.896 & 0.787 & 0.740 \\
\hline F test & $321.16^{* *}$ & $254.69 * *$ & $110.08 * *$ & $84.96 * *$ \\
\hline
\end{tabular}

Notes: The regression model (3) correlates the non-replicable forecasts, $X_{\mathrm{i}}$, and expertise, $W_{i}$, in

$$
X_{i}=W_{i} \delta_{i}+\eta_{i}, \quad \eta_{i} \sim\left(0, \sigma_{i}^{2} I\right)
$$

where $i=1$ for the initial forecast and $i=2$ for the primary forecast. Replicable expertise in (3) for the primary forecast is approximated by one-period lagged real growth, one-period lagged inflation, one period lagged initial forecast, and one period lagged primary forecast. Replicable expertise for the initial forecast replaces the one period lagged primary forecast with its two period lagged counterpart. The $\mathrm{F}$ test is a test of replicable expertise.

$*$ and $* *$ denote significance at the $5 \%$ and $1 \%$ levels, respectively. 
Table 2

Testing Bias in Replicable Initial and Primary Forecasts

(standard errors in parentheses)

\begin{tabular}{|c|c|c|c|c|}
\hline \multirow{2}{*}{$\begin{array}{l}\text { Estimation } \\
\text { Method }\end{array}$} & \multicolumn{4}{|c|}{ Inflation } \\
\hline & Intercept & $\begin{array}{c}\text { Replicable } \\
\text { Initial Forecast }\end{array}$ & $\begin{array}{c}\text { Replicable } \\
\text { Primary Forecast }\end{array}$ & Adjusted $\mathrm{R}^{2}$ \\
\hline OLS & $\begin{array}{l}-0.347 \\
(0.188)\end{array}$ & $\begin{array}{l}1.040 \\
(0.035)\end{array}$ & & 0.884 \\
\hline $\mathrm{HAC}$ & {$[0.176]$} & {$[0.090]$} & & \\
\hline OLS & $\begin{array}{l}-0.042 \\
(0.180)\end{array}$ & & $\begin{array}{c}1.001 \\
(0.033)\end{array}$ & 0.885 \\
\hline HAC & [0.155] & & [0.084] & \\
\hline \multirow{2}{*}{$\begin{array}{l}\text { Estimation } \\
\text { Method }\end{array}$} & \multicolumn{4}{|c|}{ Real Growth Rate } \\
\hline & Intercept & $\begin{array}{c}\text { Replicable } \\
\text { Initial Forecast }\end{array}$ & $\begin{array}{c}\text { Replicable } \\
\text { Primary Forecast }\end{array}$ & Adjusted $\mathrm{R}^{2}$ \\
\hline OLS & $\begin{array}{l}-0.662 \\
(0.495)\end{array}$ & $\begin{array}{l}1.223 * * \\
(0.077)\end{array}$ & & 0.681 \\
\hline HAC & [0.619] & {$[0.096]$} & & \\
\hline OLS & $\begin{array}{c}-2.694 * * \\
(0.642)\end{array}$ & & $\begin{array}{l}1.540 * * \\
(0.101)\end{array}$ & 0.665 \\
\hline HAC & [0.788] & & [0.143] & \\
\hline
\end{tabular}

Notes: The regression model is

$$
y=\gamma_{i}+\beta_{i} \hat{X}_{i}+\varepsilon_{i},
$$

where $i=1$ for the initial forecast and $i=2$ for the primary forecast. Newey-West HAC standard errors are given in brackets.

** denotes significance at the $1 \%$ level. The null hypothesis of no bias corresponds with $\gamma_{i}=0$ and $\beta_{i}=1$ 
Table 3

Testing Bias in Non-Replicable Initial and Primary Forecasts (standard errors in parentheses)

\begin{tabular}{|c|c|c|c|c|}
\hline \multirow{2}{*}{$\begin{array}{l}\text { Estimation } \\
\text { Method }\end{array}$} & \multicolumn{4}{|c|}{ Inflation } \\
\hline & Intercept & $\begin{array}{l}\text { Non-replicable } \\
\text { Initial Forecast }\end{array}$ & $\begin{array}{c}\text { Non-replicable } \\
\text { Primary Forecast }\end{array}$ & Adjusted $\mathrm{R}^{2}$ \\
\hline OLS & $\begin{array}{c}-0.336^{* *} \\
(0.110)\end{array}$ & $\begin{array}{c}1.035 \\
(0.020)\end{array}$ & & 0.958 \\
\hline GMM & $\begin{array}{c}-0.463^{* *} \\
(0.095)\end{array}$ & $\begin{array}{l}1.098 * * \\
(0.027)\end{array}$ & & 0.955 \\
\hline OLS & $\begin{array}{l}-0.048 \\
(0.051)\end{array}$ & & $\begin{array}{c}1.003 \\
(0.009)\end{array}$ & 0.990 \\
\hline GMM & $\begin{array}{l}-0.034 \\
(0.035)\end{array}$ & & $\begin{array}{c}1.018 \\
(0.012)\end{array}$ & 0.990 \\
\hline \multirow{2}{*}{$\begin{array}{l}\text { Estimation } \\
\text { Method }\end{array}$} & \multicolumn{4}{|c|}{ Real Growth Rate } \\
\hline & Intercept & $\begin{array}{l}\text { Non-replicable } \\
\text { Initial Forecast }\end{array}$ & $\begin{array}{c}\text { Non-replicable } \\
\text { Primary Forecast }\end{array}$ & Adjusted $\mathrm{R}^{2}$ \\
\hline OLS & $\begin{array}{l}-0.484 \\
(0.317)\end{array}$ & $\begin{array}{l}1.195^{* *} \\
(0.048)\end{array}$ & & 0.839 \\
\hline GMM & $\begin{array}{c}-1.487 * * \\
(0.481)\end{array}$ & $\begin{array}{l}1.329 * * \\
(0.070)\end{array}$ & & 0.819 \\
\hline OLS & $\begin{array}{l}-0.127 \\
(0.128)\end{array}$ & & $\begin{array}{l}1.119 * * \\
(0.019)\end{array}$ & 0.968 \\
\hline GMM & $\begin{array}{l}-0.150 \\
(0.146)\end{array}$ & & $\begin{array}{l}1.122 * * \\
(0.022)\end{array}$ & 0.967 \\
\hline
\end{tabular}

Notes: The regression model is

$$
y=\gamma_{i}+\beta_{i} X_{i}+\left(u_{i}-\beta_{i} \eta_{i}\right)
$$

where $i=1$ for the initial forecast and $i=2$ for the primary forecast. The instrument list for GMM for the primary forecast includes one-period lagged real growth, one-period lagged inflation, one-period lagged initial forecast, and one-period lagged primary forecast. The instrument set for the initial forecast replaces the one period lagged primary forecast with its two period lagged counterpart.

** denotes significance at the $1 \%$ level. The null hypothesis of no bias corresponds with $\gamma_{i}=0$ and $\beta_{i}=1$. 
Table 4

Accuracy of Replicable (R) and Non-Replicable (NR) Initial and Primary Forecasts

\begin{tabular}{|c|c|c|c|c|}
\hline \multirow[b]{2}{*}{ Forecasts } & \multicolumn{2}{|c|}{ Inflation } & \multicolumn{2}{|c|}{ Real Growth Rate } \\
\hline & RMSE & MAD & RMSE & MAD \\
\hline Initial & $\begin{array}{cc}\text { R: } & 2.55 \\
\text { NR: } & 0.95 \\
& \\
\text { Reduction: } 63 \%\end{array}$ & $\begin{array}{cc}\text { R: } & 1.11 \\
\text { NR: } & 0.69 \\
& \\
\text { Reduction: } 38 \%\end{array}$ & $\begin{array}{c}\text { R: } 4.16 \\
\text { NR: } 2.53 \\
\\
\text { Reduction } 39 \%\end{array}$ & $\begin{array}{cc}\text { R: } & 1.49 \\
\text { NR: } & 1.19 \\
& \\
\text { Reduction: } 20 \%\end{array}$ \\
\hline Primary & $\begin{array}{cc}\text { R: } & 2.44 \\
\text { NR: } & 0.21 \\
\text { Reduction: } 91 \%\end{array}$ & $\begin{array}{cc}\text { R: } & 1.07 \\
\text { NR: } & 0.14 \\
& \\
\text { Reduction: } 87 \%\end{array}$ & $\begin{array}{cc}\text { R: } & 4.91 \\
\text { NR: } & 0.86 \\
& \\
\text { Reduction: } 82 \%\end{array}$ & $\begin{array}{cc}\text { R: } & 1.60 \\
\text { NR: } & 0.72 \\
& \\
\text { Reduction: } 55 \%\end{array}$ \\
\hline
\end{tabular}

Notes: RMSE and MAD denote root mean square error and mean absolute deviation, respectively. The sample period is 1978 Q1 to 2008 Q1.

Data source: Quarterly National Economic Trends, Directorate-General of Budget, Accounting and Statistics, Executive Yuan, Taiwan, 1978-2008. 


\section{Figure 1}

Inflation Rate, Initial Forecasts and Primary Forecasts

(Data set is from 1978 Q1 to 2008 Q1)

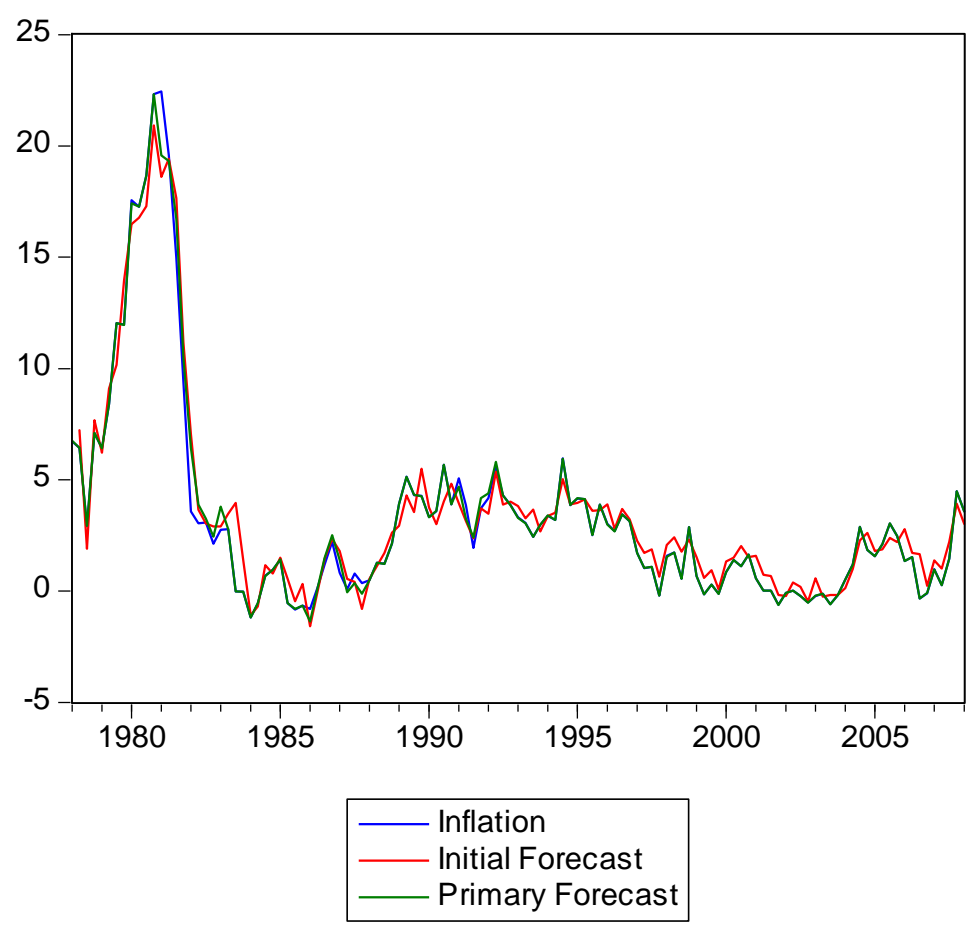


Figure 2

Real Growth Rate, Initial Forecasts and Primary Forecasts

(Data set is from 1978 Q1 to 2008 Q1)

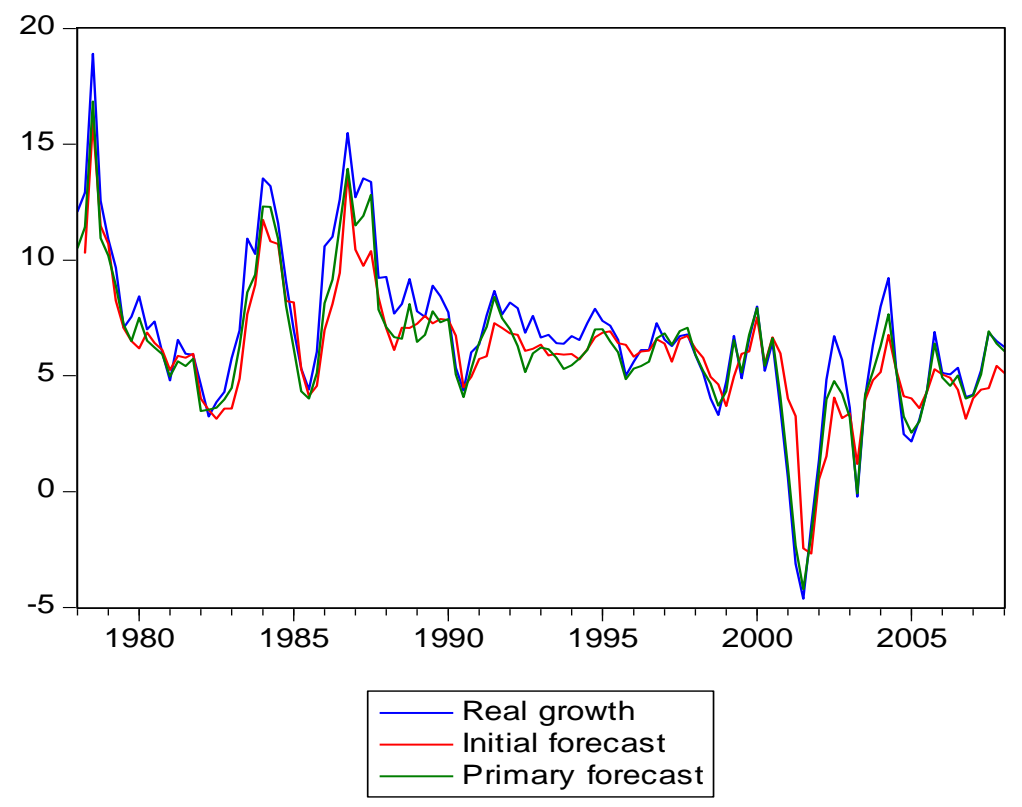




\section{References}

Fiebig, D.G., M. McAleer and R. Bartels (1992), Properties of ordinary least squares estimators in regression models with non-spherical disturbances, Journal of Econometrics, 54, 321-334.

Fildes, R., P. Goodwin, M. Lawrence and K. Nikopoulos (2009), Effective forecasting and judgmental adjustments: an empirical evaluation and strategies for improvement in supplychain planning, International Journal of Forecasting, 25, 3-23.

Franses, P.H. (2008), Merging models and experts, International Journal of Forecasting, 24(1), 3133.

Franses, P.H. and R. Legerstee (2009), Properties of expert adjustments on model-based SKU-level forecasts, International Journal of Forecasting, 25, 35-47.

Franses, P.H., M. McAleer and R. Legerstee (2009), Expert opinion versus expertise in forecasting, Statistica Neerlandica, 63, 334-346.

Goodwin, P. (2000), Improving the voluntary integration of statistical forecasts and judgement, International Journal of Forecasting, 16, 85-99.

McAleer, M. (1992), Efficient estimation: the Rao-Zyskind condition, Kruskal's theorem and ordinary least squares, Economic Record, 68, 65-72.

McAleer, M. and C. McKenzie (1991), When are two step estimators efficient?, Econometric Reviews, 10, 235-252.

Oxley, L. and M. McAleer (1993), Econometric issues in macroeconomic models with generated regressors, Journal of Economic Surveys, 7, 1-40.

Pagan, A.R. (1984), Econometric issues in the analysis of regressions with generated regressors, International Economic Review, 25, 221-247.

Patton, A.J. and A. Timmermann (2007a), Properties of optimal forecasts under asymmetric loss and nonlinearity, Journal of Econometrics, 140, 884-918.

Patton, A.J. and A. Timmermann (2007b), Testing forecast optimality under unknown loss, Journal of the American Statistical Association, 102, 1172-1184.

Smith, J. and M. McAleer (1994), Newey-West covariance matrix estimates for models with generated regressors, Applied Economics, 26, 635-640. 